\title{
DECENTRALIZATION AND FUEL SUBSIDIES
}

\author{
by
}

\section{Massimiliano Ferraresi ${ }^{\dagger}$ Christos Kotsogiannis $^{a}$ and Leonzio Rizzo ${ }^{b, c}$}

Abstract: This paper explores the role of decentralization in explaining variation in fuel subsidies across countries. Using panel data over the period 1998-2008 and for 108 countries, it emerges that the effect of 'decentralization' (taken to be an increase in the number of government levels) broadly decreases both diesel and gasoline subsidies, with this effect being more pronounced when the level of political accountability is low. For developing countries, for which political accountability is low, decentralization decreases gasoline and diesel subsidies by at least $6.98 \%$ and $12.99 \%$, respectively. For developed countries, for which political accountability is high, decentralization does not have any impact on both gasoline and diesel. What this evidence points to is that in developing economies, where voters are poorly informed and accountability is low, decentralization, appears to be associated with lower fuel subsidies.

Keywords: Fuel-price subsidies; multi-leveled governance; federalism; decentralization; share responsibility

JEL classification: O23; H77; D72

${ }^{\dagger}$ European Commission - DG Joint Research Centre Directorate I Competences - Modelling, Indicators and Impact Evaluation Unit, Via E.Fermi 2749, TP 361 Ispra (VA), I-21027, Italy and University of Ferrara.

${ }^{a}$ Department of Economics, University of Exeter Business School, Streatham Court, Rennes Drive, Exeter EX4 4PU, England, UK and Tax Administration Research Centre (TARC). CESifo, Germany.

${ }^{b}$ University of Ferrara, Via Voltapaletto 11, 44122 Ferrara, Italy and Institut d'Economia Barcelona (IEB).

${ }^{c}$ Corresponding author.

Emails: frrmsm@unife.it (Ferraresi), c.kotsogiannis@exeter.ac.uk (Kotsogiannis), leonzio.rizzo@unife.it (Rizzo)

Acknowledgements: The paper has benefited greatly from comments and advice from Jan Auerbach, Cees Van Beers, Georgios Chrysanthou, Phil Keefer, Michael Keen, Antonio Savoia and Jon Strand. We also thank seminar audiences at Exeter University, University of Siegen and the World Bank. Riccardo Secomandi and Lin Shi has provided excellent assistance with the data. The views expressed in this paper are those of the authors and do not necessarily represent those of the European Commission, nor those of the World Bank. Any remaining errors are, of course, ours. Part of this paper was written while Kotsogiannis was visiting the University of Ferrara the hospitality of which is gratefully acknowledged. Leonzio Rizzo thankfully acknowledges financial support from the Spanish Ministry of Economy and Competitiveness (ECO2012-37873) and also from Bando FIR. 


\section{Introduction}

Fuel price-subsidies - meaning deviations of domestic actual prices from specified benchmark ones - are among the most common public policy instruments in current use, Coady et al., (2006). ${ }^{1}$ They are causing significant inefficiencies, to the extent that international organizations, such as the IMF, the World Bank and the OECD, have recently called for their phasing out. And there has been declared commitment to the undertaking of significant reforms by the G20 leaders. In the G20 Pittsburgh Declaration the G20 leaders have agreed

'[t]o phase out and rationalize over the medium term inefficient fossil-fuel subsidies while providing targeted support for the poorest. Inefficient fossilfuel subsidies encourage wasteful consumption, reduce our energy security, impede investment in clean energy sources and undermine efforts to deal with the threat of climate change.' (2009, paragraph 24).

In similar vein, and linking fuel subsidies to climate change, the OECD Secretary-General Angel Gurría has recently emphasised the need for fossil fuel reforms. As he vividly puts it

'[t]he time is ripe for countries to demonstrate they are serious about combating climate change, and reforming harmful fossil fuel support is a good place to start,..., [g]overnments are spending almost twice as much money supporting fossil fuels as is needed to meet the climate-finance objectives set by the international community, which call for mobilising 100 billion US dollars a year by 2020. We must change the course.' Opening remarks, 21 September 2015, Paris.

It is evident that energy reforms will continue to be high on the policy agenda partly because of the need for countries ${ }^{2}$ to act on their emission reduction pledges, but also because of the wider negative effects they have on economic development. ${ }^{3}$ But, though fossil fuel subsidies are inefficient instruments, and there is therefore a strong economic case for removing them, in reality reforms have proven extremely difficult. ${ }^{4}$ Coady et al.,

\footnotetext{
${ }^{1}$ There are many types of subsidies and can be provided along the value chain of fossil fuels from exploration, to production and consumption. Here, and driven by data availability, the focus is on gasoline and diesel subsidies. They are also widespread: In the data set used in this paper $11 \%$ of the countries subsidise gasoline and about $23 \%$ subsidise diesel. Gasoline subsidies are almost equally distributed (and fairly stable across years) between developed and developing countries with $53 \%$ of countries subsidising gasoline being developing countries, whereas for diesel subsidies $65 \%$ of countries are developing. Developed countries are considered to be all those belonging to the two groups classified by the World Bank as upper middle-income and high-income countries, whereas developing countries are classified as all those belonging to the two groups of low-income and lower middle-income countries.

${ }^{2}$ Following, for example, the December 2015 Paris Agreement on Climate Change.

${ }^{3} \mathrm{~A}$ concern amplified by the recent volatility in food and energy prices and the ongoing economic crisis.

${ }^{4}$ It is well know that in perfectly competitive markets, price subsidies, since actual prices deviate from marginal-cost pricing, misallocate resources, thereby generating economic efficiency losses. They are
} 
(2016), for example, have estimated worldwide subsidies to be US\$ 4.9 trillion in 2013 and US\$ 5.3 trillion in 2015 (equivalent to $6.5 \%$ of global GDP for both years). ${ }^{5}$ In terms of revenues, the IMF (2013) estimates that consumption of petroleum, electricity, natural gas and coal were subsidised by about $2 \%$ of total government revenue in 2011 . The popular justification that is typically given for such extensive use of fuel price subsidies is that it is the only instrument that can be used to alleviate energy poverty. Fuel subsidies have been shown by others to be inefficient policies as the benefits from subsidies typically accrue to middle-and high-income consumers as poor households are often unable to afford even subsidized energy. And there are of course better instruments that target redistribution more efficiently. ${ }^{6}$

But if they are not a particularly effective instruments for redistribution why are they so popular with policymakers? Why is reforming them so hard? Broad political economy aspects can explain this behaviour, including (a view that will be central to the argument in this paper) the strand of the literature that considers subsidies to be salient instruments implying that the popularity of the policymakers to households (voters) is greater if the price of fuel is low relative to the case the fuel-price has been determined by market conditions. ${ }^{7}$ And it is a very visible instrument too. For low-income countries, for example, sudden rises in energy costs have an immediate impact on households' budgets and they spill very quickly into public unrest, with examples of such episodes taking place in Venezuela in 1989, Yemen in 2005, Cameroon in 2008, and Bolivia in 2010. In Nigeria, to give another example, a subsidy cut in 2012 - which resulted in doubling petrol prices overnight - was met with protests that brought the country into a standstill until the subsidies were reintroduced. Neither the protests nor the response,

undesirable from a distributional perspective, since any desired redistribution can be achieved with more efficient instruments; have spillover effects; put significant strain on public finances with detrimental effects on public sector debts; encourage socially wasteful activities, such as smuggling and black-market transactions; exacerbate energy volatility, since market demand is not very responsive to international prices, and benefit, perversely, the rich (as they are significant users of energy) far more than the poor; and impede economic growth, in particular so in developing countries. In a number of countries fuel subsidies can be as large as public education and health expenditure, Coady et al., (2006). See also Arze del Granado et al., (2012), Clements et al., (2007), Ellis (2010), UNEP (2008), OECD (2010), and IMF (2013). There are many externalities associated with fuel subsidies (as a consequence of excessive use of fuel). These include soil salinization (due to excessive irrigation), poor water quality (due to excessive use of fertilizers), and increases in global pollution (due to excessive emissions). International energy prices have increased substantially over the past few years (natural gas being an exception). Despite this many low- and middle-income economies have been reluctant to adjust their domestic energy prices to reflect these increases. The resulting fiscal costs have been substantial and pose even greater fiscal risks for these countries if international prices continue to increase as they put immense pressure on fiscal budgets.

${ }^{5}$ The total global deadweight loss from fuel subsidies (gasoline and diesel) in 2012 has been estimated to be US\$ 44 billion, Davis (2014).

${ }^{6}$ See Arze del Granado et al., (2012), IEA (2011), and Sterner ed. (2012).

${ }^{7}$ Subsidised fuel (and food) has been frequently seen, too, as part of an implicit contract between governments and their populations. Besley and Prat (2006) explore political incentives more generally, whereas Beers and Strand (2013) relate the political incentives to subsidies. See also Kotsogiannis and Rizzo (2016). 
however, are confined to low-income or developing countries. The UK in 2000 experienced significant protests from hauliers against high petrol prices. The response of the government was to announce a range of tax cuts for motorists a couple of months later, resisting from sharp rises in fuel duties for years afterwards. Interestingly, subsidies are often abolished and then re-imposed after public demonstrations.

Evidently, there are complex political economy incentives behind fuel subsidies but intuition would suggest (and the examples above somewhat confirm) that the visibility of the policy is a key determinant and, therefore, the government architecture of a country is an important determinant of their level: the point here being (and one that we make more precise shortly) that any incentive for political gain can be weakened by a multi-leveled political architecture of governance ('decentralization'). ${ }^{8}$ The reason for this relates to the fact that voters, upon realising the effect of the policy, cannot assign probability one to the government level that enacted the policy. It is this issue that this paper deals with. In particular, and in the most general form, the paper asks: how does the existence of a multi-leveled government structure affect fuel pricing? Or, to put it differently, is a hierarchical structure of governance conducive to low or high fuel subsidies? One cannot, of course, hope to find an unambiguous answer to the central question that has been the subject of a significant literature - the desirability or otherwise of fiscal decentralization - from a model that is specifically designed to address issues of subsidies. One can, however, hope to find evidence and clarify some of the deeper economic forces at work, developing some sense, for example, of the conditions under which decentralization is likely to be desirable from that perspective. Work on this issue is, surprisingly, rather limited: one of the reasons being the paucity of reliable data on subsidies. To overcome this obstacle the focus is on gasoline (and diesel) prices. The essence of this paper is, therefore, to examine the determinants of gasoline (diesel) subsidies, paying particular attention to the degree of decentralization and its interplay with accountability.

Making use of a unique data set for 108 countries and for the period 1998-2008, it is shown that decentralization (taken to be an increase in the number of government levels) broadly decreases both diesel and gasoline subsidies, with this effect, interestingly, being more pronounced when the level of political accountability is low. In particular, for developing countries decentralization decreases gasoline and diesel subsidies by $6.98 \%$ and $12.99 \%$, respectively, relative to the sub-sample average, where the subsample median level of accountability is assumed, whereas for developed countries, decentralization does not have any impact on both gasoline and diesel subsidies for any subsample median level of accountability. What does this all points to? Interestingly, it points towards the possibility that, in general, in developing economies, where voters are poorly informed and accountability is low, fuel subsides will be an inefficient policy but it will be more

\footnotetext{
${ }^{8}$ Taken to be a system of governance which disperses authority between 'regional governments and a central government in such a way that each kind of government has some activities on which it makes final decisions', Riker (1987).
} 
so in the absence of multi-leveled governance.

This paper contributes to the fast growing literature, termed the second-generation theory of fiscal federalism, that focuses on the political processes and the behavior of political agents and their effects on fiscal outcomes in federal systems (see Oates (2005), and Weingast (2006) for comprehensive surveys on this literature). Evidently, this interest stems from the view that decentralization is the appropriate government structure to ensure an efficient allocation of resources, to promote accountability and to enhance economic growth. The literature in this area is rich in papers and policy documents, reflecting a resurgence of interest in decentralization around the world during the last decade, both in developed and developing world. The implementation of decentralization policies, however, has varied substantially across countries and, in many cases, it has been problematic and not very successful, in particular so in developing countriesand they are those with particular governance and state-building challenges. There are many reasons for this, including the strand of the literature that stresses the need for an effective allocation of responsibilities across levels of government which asymmetric information across those levels imped from achieving. ${ }^{9}$

The plan of the paper is as follows. Section 2 takes a look at a very simple model whose sole purpose is to fix ideas by describing the effect of decentralization on fuel prices. Section 3 defines the key variables of the analysis (subsidies, decentralisation and accountability). Section 4 introduces the econometrics methodology, while Section 5 explores the results and Section 6 performs robustness checks. Finally, Section 7 summarises and concludes.

\section{$2 \quad$ Fixing ideas and stating the hypotheses}

This section sets out a simple framework whose sole purpose is to fix ideas. At its heart is identifying a mechanism that links the incentive of the central government to subsidise prices, when policy is set within an economy with many levels of government each of which enjoys some autonomy in fiscal decisions, not necessarily over the same policy instrument, and the households cannot perfectly distinguish which level is setting the price. $^{10}$

\footnotetext{
${ }^{9}$ Expressions of this idea vary, ranging from the role of heterogeneity of information among voters across territories with different capabilities, Boffa et al., (2016), to the inability of voters to hold each level of government individually accountable for its contribution to public good provision, Joanis (2014). This is an issue of particular interest for developing countries, where accountability of government is in general lower than in developed countries, Bardhan and Mookherjee (2006a,b) and Mani and Mukand (2007), so rent seeking behaviour from opportunistic policymakers is easier. There are of course other factors that might play a critical role, such as the lack of hard budget constraints and dysfunctional (especially in developing countries) markets, Sorens (2016).

${ }^{10}$ This feature appears also in Joanis (2014) who analyses the interplay between public good provision across levels of government that share responsibility and accountability.
} 
It will help matters to cast the analysis in terms of a subsidy (taken to mean a price offered to households/voters which is lower than it would be had the government not intervened), denoted by $\sigma$. Suppose further that this subsidy requires some 'effort' (perhaps related to the effort required for finding resources to financing the subsidy) on the part of the central government and takes the simple form

$$
\sigma(e)=e
$$

Households prefer low prices and are myopic about that this might entail increases in other prices/taxes. What this translates to is that a higher subsidy induced by higher effort increases the benefit of the incumbent policy maker staying in office. The idea here being that, through higher effort, higher subsidy is rewarded by a group of needy voters with more likely reelection. This benefit is, however, decreasing in the number of government levels, denoted by $\lambda>0$ (treated here as a continuous variable), as voters do not assign probability 1 to the central government having enacted the policy. This, it has to be noted, is somewhat reminiscent of the externality caused when different levels of government tax the same tax base, ${ }^{11}$ Keen and Kotsogiannis (2002). Here there is indeed an externality which is not caused by a fiscal instrument directly, but by the myopia of households/voters exerted in assigning the policy outcome to the government that has enacted the policy.

Denote the benefit by ${ }^{12} b(\sigma(e), \lambda)$, assumed to be strictly concave in the level of effort, with $^{13} b_{e}(e, \lambda)>0$ and $b_{e e}(e, \lambda)<0$. It is also assumed that $b_{e \lambda}(e, \lambda)<0$ and so an increase in the number of government levels, $\lambda$, reduces the gain from providing effort, as this reduces the likelihood that this policy is enacted by the central government. The cost to the government of exerted effort is $c(e, \alpha)$ : this cost is assumed to be strictly increasing and convex in the amount of effort, and so $c_{e}(e, \alpha)>0$ and $c_{e e}(e, \alpha)>0$, and to depend on the level of some accountability parameter, $\alpha$, in the sense that $c_{e \alpha}(e, \alpha)>0$. What this captures is that implementing the subsidy is costly, a cost that depends on accountability. ${ }^{14}$

\footnotetext{
${ }^{11}$ While the precise characterisation of the equilibrium is side-stepped (including the other levels of government - being parametrically captured), the reduced form of the simple structure is nevertheless useful in identifying the main mechanism and guide the empirics.

${ }^{12}$ The exact process for which this benefit is derived is not modelled but it can take the form of the expected rent derived in a two period model, as in, among others, Besley and Case (1995), Besley and Smart (2007), Kotsogiannis and Schwager (2008). The expected rent depends on the probability to be re-elected, whose perception by voters is distorted when voters do not clearly understand who enacted the policy, Joanis (2014).

${ }^{13}$ And making use of (1). A subscript denotes a derivative.

${ }^{14}$ The presumption is that in developing countries, where accountability is low, the impact of accountability on the cost will be much lower than in developed countries where voters are better informed regarding political decisions, and so accountability is high. There are examples of this. Aizenman and Jinjarak (2008), for example, show that political instability is associated with reduced effectiveness of VAT.
} 
The central government then, by choice of $e$, maximises

$$
v(e, \lambda, \alpha)=b(e, \lambda)-c(e, \alpha)
$$

with the necessary condition of this maximization problem being (a subscript denotes derivative) given by

$$
v_{e}(e, \lambda, \alpha)=b_{e}(e, \lambda)-c_{e}(e, \alpha)=0,
$$

and with sufficiency being satisfied by the properties of the $b(\cdot)$ and $c(\cdot)$ functions. Of particular interest is the dependence of $e(\lambda, \alpha)$ on $\lambda$ and $\alpha$. Routine differentiation of (3) gives

$$
e_{\lambda}=-\frac{b_{e \lambda}}{b_{e e}-c_{e e}}<0 \quad ; \quad e_{\alpha}=\frac{c_{e \alpha}}{b_{e e}-c_{e e}}<0,
$$

where the inequalities follow from $b_{e \lambda}<0$ and $c_{e \alpha}>0$.

Also

$$
e_{\alpha \lambda}=-\frac{b_{e e \lambda} c_{e \alpha}}{\left(b_{e e}-c_{e e}\right)^{2}},
$$

with its sign, unsurprisingly, being depended on the third derivative of $b(e, \lambda, \alpha)$. We are being agnostic about this - though it is natural to assume that an increase in the number of government levels, $\lambda$, dampens the effect of accountability, $\alpha$, on effort, $e$, (and so the subsidy, $\sigma)$.

As long as more accountability of the elected government reduces the marginal gain for the central government, then more accountability reduces the incentive of the central government to subsidise fuel. This will be the case, for given $\lambda$, if an increase in accountability, $\alpha$, reduces the political gain of the policy enacted by the central government (favourable for voters, on average) which loses its appeal as policy that buys popularity for the central government. Similarly, $e_{\lambda}$ is negative as long as the increase in the number of government levels, $\lambda$, reduces the marginal gain for the central government of increasing the subsidy.

Equipped with the preceding discussion the following two hypotheses are empirically tested:

Hypothesis 1 For given accountability, $\alpha$, an increase in the number of government levels, $\lambda$, reduces fuel subsidies, $\sigma_{\lambda}<0$.

Hypothesis 2 For a given number of government levels, $\lambda$, an increase in accountability, $\alpha$, reduces fuel subsidies, $\sigma_{\alpha}<0$.

\section{Fuel subsidies: Definitions and preliminary anal- ysis}

Fossil fuel-price subsidies are typically calculated by the price-gap method (see Kosmo (1987), Larsen and Shah (1992), Coady et al., (2010), and Beers and Strand (2013)), 
which implies calculation of the difference between a benchmark price and the actual fossil fuel prices. Consumer subsidies arise when market prices-paid by consumers, including both firms (intermediate consumption) and households (final consumption) - are below a benchmark price. Producer subsidies arise when prices received by suppliers are above this benchmark. When an energy product is internationally traded, the benchmark price for calculating subsidies is based on its international price. ${ }^{15}$ The benchmark being used is the average fuel price in the United States in US\$ cents per liter. For oil importing countries the benchmark price is reduced by US $\$ 0.10$ per liter to allow for the costs of shipping the fuel from the hub to the country, whereas for oil exporting countries the benchmark price is reduced by US $\$ 0.20$ per liter. What this all implies is that

$$
\begin{aligned}
p g_{m}^{j}=\bar{p}-p^{j}-10 & \text { importing country } \\
p g_{e}^{j}=\bar{p}-p^{j}-20 & \text { exporting country }
\end{aligned}
$$

where $p g_{m}^{j}$ denotes the price gap for the $j$-th net-energy importing-country, $p g_{e}^{j}$ the price gap for the $j$-th net-energy exporting-country, $\bar{p}$ the retail pump price of a unit of energy in the US market, and $p^{j}$ the retail price of a unit of energy in the domestic market of the $j$-th country. (6) and (7) apply to both gasoline and diesel prices.

To capture accountability in a given country we make use of the variable voice - taken from the Worldwide Governance Indicator (WGI) dataset - indicating 'the perceptions of the extent to which a country's citizens are able to participate in selecting their government, as well as freedom of expression, freedom of association, and free media'. ${ }^{16}$ This variable is computed in percentiles, ranking countries from 0 (corresponding to lowest rank) to 100 (the highest rank). To capture the effect of the number of government levels, we follow the literature ${ }^{17}$ and make use of the variable tiers, defined as '.... the subset of governments in a country such that all members of this subset have jurisdictions that are contained by the same number of (other governments') jurisdictions. For instance, all governments whose jurisdictions are contained only by the jurisdiction of the national government are denoted 'first-tier' sub-national governments. All those whose jurisdictions are contained by that of the national government and that of one 'firsttier' government are 'second-tier' governments,' Treisman (2000), pp.3-4. This variable captures well the dimension of decentralization emphasised in this paper. ${ }^{18}$

Many empirical studies in the fiscal federalism literature (see, among others, Fisman and Gatti (2002), Panizza (2009)) have relied on fiscal expenditure and revenue data from the International Monetary Fund's (IMF) Government Finance Statistics (GFS) by using

\footnotetext{
${ }^{15}$ This approach to measuring subsidies is often referred to as the price-gap approach and is widely by international agencies. For more on this see IMF (2013).

${ }^{16}$ The definitions of the variables are in $431 \mathrm{~A}$.

${ }^{17}$ See, for example, Kessing et al., (2007), Fan et al., (2009), and Albornoz and Cabrales (2013).

${ }^{18}$ And the variable $\lambda$ in Section 2.
} 
the ratio of central to local tax revenues (or expenditures), Dziobek et al., (2011). These data have some obvious limitations. Firstly, they are somewhat incomplete substantially reducing the number of observations. Secondly, looking at fiscal decentralization without taking account of the actual control local governments have over the collection and spending might be misleading, as an index of decentralized expenditure (or revenue) does not necessarily measure institutional decentralization (and fiscal autonomy). The reason for this is that quite often local expenditures are centrally mandated expenditures and local revenues are collected locally, but without the local authorities having autonomy over either the tax rate or base. Moreover, since gasoline and diesel subsidies are, typically, a central governments responsibility they can affect centralized expenditure and revenue giving rise to an endogeneity problem in the estimation procedure. ${ }^{19}$

Figure 1 plots the relationship between gasoline (diesel) subsidy and the accountability index, showing that as accountability increases gasoline (diesel) subsidy decreases. Putting this in the context of Section 2, what this suggests is that an increase in accountability implies more transparency in policy and, therefore, an inefficient policy (like that of subsidising fuel) is more costly for the policymakers. The implication of this is that an increase in accountability, for a given level of government levels, induces a reduction in subsidies.

\section{Insert Figure 1 here.}

But does the number of government levels have a role in decreasing subsidies? Grouping countries into low and high government levels (with the threshold being the median of the number of government levels) and comparing the mean of the subsidies in the two groups, they turn out not to be significantly different from each other. However, to explore the role of the number of government levels on subsidies, we investigate whether the mean of the subsidies in the two groups depends on the per capita income level of a country. To do so we classify, using the World Bank classification, countries into low-income, lower middle-income, upper middle-income, and high-income countries. We then put together the two high-income classes and the two low-income classes and split the sample in developed and developing countries (Table 1).

\section{Insert Table 1 here.}

The former contains 423 observations, with the average per capita income being US\$ 3,452 , whereas the latter contains 480 observations with the average per capita income being US\$24,207. We turn now to the question of whether the number of government levels has a role in decreasing subsidies with its impact being different depending on whether a country is a developing or a developed one. To do so we look at the difference in mean of gasoline (diesel) subsidy between high- and low government levels sub-samples for developed and developing countries. In the former case, the difference (US\$ -0.66

\footnotetext{
${ }^{19}$ Such problem is not present in tiers which is unlikely to change according to the levels of the gasoline and diesel subsidies.
} 
cents per liter of diesel and US\$ -0.71 cents per liter of gasoline) is not statistically significant whereas in the latter case the difference (US\$ -8.32 cents per liter of diesel and US\$ -9.85 cents per liter of gasoline) is negative and statistically significant at $1 \%$ (Table 2), meaning that a high level of government layers is effective in decreasing subsidies both for diesel and gasoline only for developing countries.

All in all, the above preliminary evidence seems to suggest that for developing countrieswhere the accountability level of the government is, on average, lower than that of developed countries, 30.62 out of 100 for the former and 70.01 out of 100 for the latterdecentralization negatively affects gasoline (diesel) subsidy.

Insert Table 2 here.

The analysis now turns to the empirical estimation.

\section{Empirical analysis}

To test for the impact of accountability and decentralization on fuel subsidies, we estimate a reduced form equation of fuel-price subsidies by using a panel dataset, for the years 1998, 2000 and 2002-2008. We have also collected data prior to 1998 in order to build the lag of some of our explanatory variables. Summary statistics are presented in Appendix B.

The analysis considers the following specification

$$
s_{j t}=\phi_{t}+\pi \alpha_{j t} \lambda_{j}+\gamma \alpha_{j t}+\delta \lambda_{j}+\boldsymbol{\beta}^{\prime} \mathbf{X}_{j t}+\phi^{\prime} \mathbf{X}_{j t-1}+\phi_{j}+\epsilon_{j t}
$$

where $p_{j t}$ is price and $j$ and $t$ are, respectively, country and time indicators; $\phi_{t}$ is a year effect and $\phi_{j}$ is the random effect; $\alpha_{j t}$ is a continuous variable ranging from 0 to 100 , capturing the degree of accountability in country $j$ and year $t ; \lambda_{j}$ is a categorical variable assuming a value from 1 to 6 indicating the number of government layers; $\mathbf{X}_{j t}$ is a vector of state-specific time-varying regressors; $\mathbf{X}_{j t-1}$ is a vector of time specific lagged regressors and in particular they are income, net supply of fuel and road gasoline (diesel) fuel consumption and $\epsilon_{j t}$ is a mean zero, normally distributed random error.

Following Section 2, and the hypotheses derived there recast here in terms of the estimated equation (8), it is expected that:

Hypothesis $1 \pi \alpha_{j t}+\delta<0$, implying that an increase in the number of government levels (tiers) decreases fuel subsidies, for a given level of accountability (voice);

Hypothesis $2 \pi \lambda_{j}+\gamma<0$, implying that an increase in accountability (voice) decreases fuel subsidies, for a given number of government levels (tiers). 
Candidates for inclusion in the vector $\mathbf{X}$ are variables that affect the level of subsidies. Drawing on the literature, ${ }^{20}$ we include both economic and demographic variables, such as, population (population), its square (population2) and the inverse of population (1/population), per-capita land (land), its square (land2) and the inverse of per capita land $(1 /$ land $)$ to allow for scale economies and, per-capita income (income) proxied by the gross domestic product converted to US $\$$ using purchasing power parity rates and introduced with a one-year lag to address potential endogeneity bias. We also control for the terms-of-trade effect (capturing the possibility that importers of fuel have the incentive to reduce demand of fuel by reducing the price rate) by using the variable net supply of fuel (oil production minus oil consumption) and a general openness measure captured by the variable openness (exports plus imports of goods as quota of GDP). The specification also allows for a measure of road gasoline consumption per million inhabitants when we estimate gasoline subsidy and road diesel consumption per million inhabitants when we estimate the diesel subsidy.

To address potential endogeneity issues the variables road gasoline consumption per million inhabitants and road diesel consumption per million inhabitants, as well as the percapita income and the net supply of fuel, are introduced with a one-year lag. Finally, we control for a series of other institutional characteristics accounting for the quality of public services (government effectiveness), political stability (political stability), regulatory quality (regulatory quality), confidence of the society in the running rule of law (rule of law), control of corruption (control of corruption) and a dummy variable equals zero if a country is a democracy (democracy). Changes in the macroeconomic, or in legal and institutional environment, may also affect the countries' fiscal position, and, therefore, their ability to provide subsidies. To account for this a set of time dummies is included in the estimation.

In a reduced form equation, the fuel subsidy is normally linked to population size, as this variable influences the use of fuel. Moreover, (the level of) income can also influence the level of subsidy (since subsidies can be used as a redistributive device), and an oilexporting (oil-importing) country has the incentive to reduce (increase) the subsidy. Also the difference between total exports and imports can affect fuel subsidies, as it is also the case for road gasoline/diesel consumption, because in both case they affect domestic prices. Finally, the size of a country can also affect the domestic price level and so the subsidy level, as the larger the size of the country the higher the need to travel and, therefore, the higher the consumption of fuel and, hence, the benefit from subsidies and so lower fuel prices.

\section{Results}

We estimate equation (8), both for diesel and gasoline subsidies (the results for the latter being relegated in Appendix C) as defined in Section 3, by using a random effect

\footnotetext{
${ }^{20}$ See Beers and Strand (2013).
} 
specification. All regressions control for year effects. As it will be shown shortly below, the results confirm the two hypotheses developed in Section 2.

Central to the issues at hand is the sign of the interaction between voice and tiers in equation (5). Following Table 3, this coefficient takes the value of 0.22 , and is statistically significant at $1 \%$ implying that an increase in either variable decreases in absolute value the impact of the other on diesel subsidies. The impact of increasing the number of government levels on diesel subsidy is given by $\pi \alpha_{j t}+\delta=0.22 \times$ voice +15.09 , which is positive, and significant, as long as the level of voice is below, or equal to, the 48th percentile $^{21}$ (Hypothesis 1).

Insert Table 3 here.

Turning now to accountability, one notices, following Table 3 , that an increase in this variable implies a change in the diesel subsidy equal to $\pi \lambda_{j}+\gamma=0.22 \times$ tiers -1.50 , which is positive and significant as long as the number of government level is below, or equal to, $5 .^{22}$ (Hypothesis 2).

Strikingly, what emerges, therefore, is that the impact of decentralization on diesel subsidies can be significant if a country is characterized by low accountability. To see this, take a country (such as Congo, Tajikistan, Tunisia and Ivory Coast) which in 2007 had a level of accountability equal to 10 . Then decentralization of policy decision making implies an decrease in the diesel subsidy of US $\$-15.09+0.22 \times 10=-12.90$ cents per liter (statistically significant at $1 \%$ level). With the average price per liter of US\$ 67.02 this is a decrease of $19.24 \%$ relative to that average. Take now a country that has the median level of accountability (Ukraine, El Salvador, Mexico and Albania). In this case, decentralization of policy decision making implies a decrease in the diesel subsidy of US\$ $-15.09+0.22 \times 50=-4.15$ cents per liter (statistically significant at $10 \%$ level), corresponding to a decrease of $6.19 \%$ relative to the diesel price average. More generally, this also suggests that the decrease in subsidy due to an increase in the number of government levels is smaller the higher the level of accountability. This is because when accountability is high it is already very costly to implement a fuel subsidy which is so already low and so the decrease in subsidy due to the increase in tiers is lower than when accountability is low. ${ }^{23}$

Close inspection of the coefficients of the covariates reveal that they all have the expected signs, Beers and Strand (2013). Less immediate evident is whether these results depend on the level of income of a given country. We turn to this next.

\footnotetext{
${ }^{21}$ Notice that the variable voice ranks countries in every year in percentiles (from 0 to 100 ), according to their accountability, meaning that 0 corresponds to the lowest level of accountability and 100 corresponds to the highest level of accountability.

${ }^{22}$ Notice that the variable tiers measures the number of administrative layers in each country taking a value from 1 to 6 .

${ }^{23}$ Estimates on gasoline subsidies, relegated in the Appendix C, Col.1 - Table C1, give qualitatively similar results.
} 


\section{Impact of decentralization and accountability on diesel subsidy: Developed versus developing countries}

To explore whether the level of development matters for the level of subsidies, we modify equation (8) by interacting voice, voice $\times$ tiers and tiers with the gross national income per capita, GNI, of the country. ${ }^{24}$ To deal with the potential endogeneity we also make use of the one-year lagged GNI. We thus estimate the following specification

$$
\begin{aligned}
s_{j t} & =\phi_{t}+\pi \alpha_{j t} \lambda_{j}+\gamma \alpha_{j t}+\delta \lambda_{j}+\rho \alpha_{j t} \lambda_{j} G N I_{j t-1}+\tau \alpha_{j t} G N I_{j t-1}+ \\
& +\psi \lambda_{j} G N I_{j t-1}+\eta G N I_{j t-1}+\boldsymbol{\beta}^{\prime} \mathbf{X}_{j t}+\phi^{\prime} \mathbf{X}_{j t-1}+\phi_{j}+\epsilon_{j t}
\end{aligned}
$$

and, therefore, the impact on subsidy, $s_{j t}$, in country $j$ of adding one government level, $\lambda$ - for given level of accountability, $\alpha$, and given level of $G N I$ - is given by

$$
\frac{\triangle s_{j t}}{\Delta \lambda_{j}}=\pi \alpha_{j t}+\delta+\rho \alpha_{j t} G N I_{j t-1}+\psi G N I_{j t-1} .
$$

To interpret equation (10), take a low income country, such as Cameroon, Kyrgyzstan, Ivory Coast and Nigeria, which in 2007 was below and close to the upper bound of the first quartile of the GNI distribution ${ }^{25}$ and had the median value - with respect to the same quartile of the GNI distribution - of the accountability index 25. Then, decentralization, when evaluated at the level of GNI corresponding to the upper bound of the first quartile of its distribution (US\$1,120), implies a decrease in diesel subsidies by US $\$ 6.99$ cents (the coefficient is statistically significant at $5 \%{ }^{26}$ ), which corresponds to $12.99 \%$ of the diesel price sub-sample average (US\$ 53.82). If voice increases (while keeping the level of GNI constant) the impact of decentralization decreases whereas if GNI decreases (while keeping the level of voice constant) the impact of decentralization increases. It thus follows that, for a given median level of voice, decentralization decreases subsidies at least by $12.99 \%$ of the diesel price sub-sample average.

Take a rich country (such as the Australia, UK, France, or Canada) which in 2007 was above and close to the lower bound of the last quartile of the GNI distribution and had the median value - with respect to the same quartile of the GNI distributionof the accountability index 93. Then, decentralization, when evaluated at the level of GNI corresponding to the lower bound of the last quartile of its distribution (US\$ $18,920)^{27}$, does not have any impact on diesel subsidies (the coefficient is not statistically significant ${ }^{28}$ ). Notice that if voice increases for the same GNI, the coefficient remains not

\footnotetext{
${ }^{24}$ GNI partitions countries to low, middle-low, middle-high and high income.

${ }^{25}$ The upper bound of the first quartile of the GNI distribution corresponds, approximately, to per capita US $\$ 1,120$ below which there are, on average, 25 countries per year -225 observations.

${ }^{26}$ The coefficient is obtained by following the estimated coefficients of Col. 2 , Table 3 ; namely $-6.99=$ $0.08 \times 25-9.11+0.000002 \times 25 \times 1,120+0.00017 \times 1,120$, with $p$-value $=0.023$.

${ }^{27}$ The lower bound of the last quartileof the GNI distribution corresponds, approximately, to per capita US\$ 18,920 above which there are, on average, 25 countries per year-225 observations.

${ }^{28}$ The coefficient is obtained by following the estimated coefficients of Col. 2, Table 3 ; namely $4.04=$ $0.08 \times 93-9.11+0.000002 \times 93 \times 18,920+0.00017 \times 18,920$, with $p$-value $=0.384$.
} 
statistically significant and, if the GNI decreases, for given level of voice, the coefficient is not significant yet.

In this case, too, the impact of decentralization on the diesel subsidy for developing countries, is statistically different $(p$-value $=0.0624)$ from the impact of adding one government level on the diesel subsidy for developed countries, suggesting that decentralization leads to a decrease in diesel subsidies only for developing countries when compared to developed countries. The same conclusions hold for gasoline subsidies. ${ }^{29}$

\section{Robustness check}

The random effect specification can bias the estimation since the unobserved country characteristics can be correlated with the error term. In order to check for this possible bias we make use of the Mundlak approach (1978), which allows for the unobserved effect to be incorporated into the random model specification by including the time averages of the covariates (including time dummies) as additional explanatory variables. In this way, the estimated coefficients of the random model specification are identical to the fixed effect estimator (Wooldridge (2009)) and, therefore, the bias does not hold anymore.

We have run regressions (Col. 1, Table 4) by using the Mundlak approach and have obtained results very similar to those obtained by running the random effect specification. In particular, the coefficient of the interaction of accountability with the number of government levels is positive for the diesel subsidy, but not statistically significant, and the impact on diesel subsidies of decentralization is negative and significant as long as the level of accountability is below the 40th percentile (Hypothesis 1). The impact on diesel subsidies of enhanced accountability is negative and significant as long as the number of government level is below, or equal to, 5 (Hypothesis 2 ).

\section{Insert Table 4 here.}

We then replicate the analysis carried out for developing and developed countries, using again the Mundlak approach. In this case, too, the results are in line with those obtained by the random effect specification.

For diesel (Col. 2, Table 4), decentralization in a poor country, when evaluated for a level of GNI equals to US\$ 1,120 and for the median level of accountability of poor countries (25), implies a decrease in the diesel subsidies by at least of US $\$ 24.73$ cents (the coefficient is statistically significant at $1 \%{ }^{30}$ ). On the other hand, decentralization in a rich country, when evaluated for a level of GNI equals to US\$18,920 and for the median level of accountability of rich countries (93), has no effect on diesel subsidies. ${ }^{31}$

\footnotetext{
${ }^{29}$ See Col. 2, Table C1, in the Appendix C.

${ }^{30}$ Using the estimated coefficients of Col. 2, Table 4 in (10) gives -24.73 with $p$-value $=0.000$.

${ }^{31}$ Using the estimated coefficients of Col. 2, Table 4 in (10) gives -17.33 with $p$-value $=0.237$.
} 
The robustness analysis, carried out by adopting the Mundlak approach, therefore confirms the results emerged under the random effects estimations: That decentralization strongly impacts on diesel subsidies and that such effect is significant only for developing countries. $^{32}$

\section{Concluding remarks}

The purpose of this paper has been to address the question of whether, in practice, fuel-price subsidies are affected by the extent of decentralization, an issue of particular interest for developing countries, where accountability of government is in general lower than in developed countries. Despite the importance of understanding the link between policy and decentralization (in particular so for developing countries where fiscal capacity is limited) there has been virtually no existing evidence from such settings. The analysis has shown that when the government architecture is a decentralized one, for given level of accountability of the government, the use of a subsidy for political gain become less effective: adding one unit of government level leads to a lower level of the fuel-price subsidy. Moreover, the increase in the level of accountability of the government mitigates the former effect: the more accountable is the government the more difficult the political benefit of a distortive subsidy is.

We have investigated further whether this effect is driven by developing and/or developed countries. We found that adding one government level leads to a statistically significant decrease in diesel and gasoline subsidy for developing countries, while it has no effect for developed countries. What this all point to? Interestingly, it points towards the possibility that in developing economies where voters are poorly informed, and the assignment of functions and policy instruments to the various government levels are imperfect, fuel subsides will be an inefficient policy but it will be more so in the absence of multi-leveled governance.

\footnotetext{
${ }^{32}$ The same conclusions hold for gasoline subsidies whose results are available in Table $\mathrm{C} 2$ of the Appendix C.
} 


\section{Appendices}

\section{Appendix A: Data sources and definitions}

Gasoline (diesel) price is premium gasoline (diesel) prices measured in November each year in US\$ cents per liter. Source: Deutsche Gesellschaft fr technische Zusammenarbeit (GTZ) - https://www.giz.de/de/html/index.html.

Tiers $i(i=1,2,3,4,4.5,5,6)$ measures the number of administrative layers, as defined in Triesman (2002). The variable level $i$ takes the value of 1 if a county has $i$ level(s) of government.

Voice captures perceptions of the extent to which a country's citizens are able to participate in selecting their government, as well as freedom of expression, freedom of association, and a free media. Percentile rank indicates the country's rank among all countries covered by the aggregate indicator, with 0 corresponding to lowest rank and, 100 to highest rank. Source: Worldwide Governance Indicator (WGI). Detailed documentation of the WGI and full access to data are available at: http://info.worldbank.org/governance/wgi/

Democracy dummy variable. 1 indicates that a country was considered to be an electoral democracy for the year; 0 indicates that a country was not. Source: Freedom House, https://freedomhouse.org/report-types/freedom-world.

Population is the total population based on the de facto definition of population, which counts all residents regardless of legal status or citizenship except for refugees not permanently settled in the country of asylum, who are generally considered part of the population of their country of origin. Source: United Nations Population Division and World Population Prospects.

Domestic deflator is given for each country by the ratio of GDP in current local currency to GDP in constant local currency. We use as base year 2005. Source: World Bank national accounts data, and OECD National Accounts data files.

US deflator is given by the ratio of US GDP in current US dollars to GDP in constant US dollars. We use as base year 2005. Source: World Bank national accounts data, and OECD National Accounts data files.

Income (GDPPPP) measures the gross domestic product converted to US dollars using purchasing power parity rates. An international dollar has the same purchasing power over GDP as the US\$ has in the United States. It is calculated without making deductions for depreciation of fabricated assets or for depletion and degradation of natural resources. Data are in current international dollars. Source: World Bank, International Comparison Program database.

Net supply of fuel (oil supply-oil consumption) is given by oil supply minus oil consumption. Oil supply is measured by annual data on total oil supply and the unit is thousand barrels per day. Oil consumption is measured by annual data on total petroleum 
consumption and the unit is thousand barrels per day. Source: Energy Information Administration (EIA).

Land (area/population) is the land area per $\mathrm{km}^{2}$ divided by population. In particular, land area is a country's total area, excluding area under inland water bodies, national claims to continental shelf, and exclusive economic zones. In most cases the definition of inland water bodies includes major rivers and lakes. Source: Food and Agriculture Organization.

Openness (exports+imports)/GDP is the sum of exports and imports of goods and services measured as a share of gross domestic product. Source: World Bank national accounts data and OECD national account data.

Road gasoline fuel consumption is road sector gasoline fuel consumption (kt of oil gasoline is light hydrocarbon oil use in internal combustion engine such as motor vehicles, excluding aircraft). Source: International Road Federation, World Road Statistics and International Energy Agency.

Road diesel fuel consumption is road sector diesel fuel consumption (kt of oil equivalent. Diesel is heavy oils used as a fuel for internal combustion in diesel engines). Source: International Road Federation, World Road Statistics and International Energy Agency.

Government effectiveness captures perceptions of the quality of public services, the quality of the civil service and the degree of its independence from political pressures, the quality of policy formulation and implementation, and the credibility of the government's commitment to such policies. Percentile rank indicates the country's rank among all countries covered by the aggregate indicator, with 0 corresponding to lowest rank and, 100 to highest rank. Source: Worldwide Governance Indicator (WGI). Detailed documentation of the WGI and full access to data are available at: http://info.worldbank.org/governance/wgi/

Political stability and absence of violence/terrorism captures perceptions of the likelihood that the government will be destabilized or overthrown by unconstitutional or violent mean, including politically-motivated violence and terrorism. Percentile rank indicates the country's rank among all countries covered by the aggregate indicator, with 0 corresponding to lowest rank and, 100 to highest rank. Source: Worldwide Governance Indicator (WGI). Detailed documentation of the WGI and full access to data are available at: http://info.worldbank.org/governance/wgi/

Regulatory quality captures perceptions of the ability of the government to formulate and implement sound policies and regulations that permit and promote private sector development. Percentile rank indicates the country's rank among all countries covered by the aggregate indicator, with 0 corresponding to lowest rank and, 100 to highest rank. Source: Worldwide Governance Indicator (WGI). Detailed documentation of the WGI and full access to data are available at: http://info.worldbank.org/governance/wgi/ 
Rule of law captures perceptions of the extent to which agents have confidence in and abide by the rules of society, and in particular the quality of contract enforcement, property rights, the police, and the courts, as well as the likelihood of crime and violence. Percentile rank indicates the country's rank among all countries covered by the aggregate indicator, with 0 corresponding to lowest rank and, 100 to highest rank. Source: Worldwide Governance Indicator (WGI). Detailed documentation of the WGI and full access to data are available at: http://info.worldbank.org/governance/wgi/

Control of corruption captures perceptions of the extent to which public power is exercised for private gain, including both petty and grand forms of corruption, as well as 'capture' of the state by elites and private interests. Percentile rank indicates the country's rank among all countries covered by the aggregate indicator, with 0 corresponding to lowest rank and, 100 to highest rank. Source: Worldwide Governance Indicator (WGI). Detailed documentation of the WGI and full access to data are available at: http://info.worldbank.org/governance/wgi/

GNI based on purchasing power parity is gross national income (GNI) converted to international dollars using purchasing power parity rates. An international dollar has the same purchasing power over GNI as a U.S. dollar has in the United States. GNI is the sum of value added by all resident producers plus any product taxes (less subsidies) not included in the valuation of output plus net receipts of primary income (compensation of employees and property income) from abroad. Source: World Bank

\section{Appendix B: Summary Statistics}

Insert Tables B1 and B2 here.

\section{Appendix C: Results based on gasoline subsidies}

Insert results for gasoline here. 


\section{References}

Aizenman, J., and Jinjarak, Y. (2008). The collection efficiency of the Value Added Tax: Theory and International Evidence,' Journal of International Trade and Economic Development, 17, 391-410.

Albornoz, F., and Cabrales, A. (2013). Decentralization, political competition and corruption. Journal of Development Economics, 105, 103-111.

Arze del Granado, J., Coady, D., and Gillingham, R. (2012). The unequal benefits of fuel subsidies: A review of evidence for developing countries. World Development 40 (November), 2234-2248.

Bardhan, P., and Mookherjee, D. (2006a). Decentralization and Local Governance in Developing Countries. MIT Press.

Bardhan, P., and Mookherjee, D. (2006b) The rise of Local Governments: An Overview. In Bardhan and Mookherjee (Eds).

Beers, van C., and Strand, J. (2013). The political determinants of fossil fuel pricing. Policy Research Working Paper No. 6470. World Bank, Washington, DC.

Besley, T., and Case, A. (1995). Incumbent Behavior: Vote-Seeking, Tax-Setting, and Yardstick Competition. American Economic Review, 85, 25-45.

Besley, T., and Prat, A. (2006). Handcuffs for the Grabbing Hard? Media capture and Government Accountability. American Economic Review, 96, 720-736.

Besley, T., and Smart, M. (2007). Fiscal restraints and voter welfare. Journal of Public Economics, 91, 755-773.

Boffa, F., Piolatto, A., and Ponzetto, G.A.M. (2016). Political centralization and government accountability. The Quarterly Journal of Economics, doi: 10.1093/qje/qjv035, $381-422$.

Clements, B., Jung, H.S., and Gupta, S. (2007). Real and Distributive Effects of Petroleum Price Liberalization: The Case of Indonesia. The Developing Economies, 45, 220-237.

Coady, D., El-Said, M., Gillingham, R., Kpodar, K., Medas, P., and Newhouse, D. (2006). The magnitude and distribution of fuel subsidies: Evidence from Bolivia, Ghana, Jordan, Mali, and Sri Lanka, IMF Working Paper 247.

Coady, D., Gillingham, R. Ossowski, R., Piotrowaski, J., Tareq, S., and Tyson, J. (2010). Petroleum Product Subsidies: Costly, Inequitable and Rising, IMF Staff Position Note SPN/10/05. 
Coady, D., Parry, I., Sears, L., and Shang, B. (2016). How large are global enrgy subsidies? CESifo Working Paper No. 5814.

Davis, L. (2014). The economic cost of global fuel subsidies. American Economic Review: Papers and Proceedings, 104(4), 581-585.

Dziobek, C., Gutierrez Mangas, C., and Kufa, P. (2011). Measuring Fiscal Decentralization: Exploring the IMF's Databases. IMF working paper 111/126.

Ellis, J. (2010). The Effects of Fossil-Fuel Subsidy Reform: A Review of Modelling and Empirical Studies. In Untold Billions: Fossil-Fuel Subsidies Their Impacts and the Path to Reform. Geneva: Global Subsidies Initiative.

Fan, C. S., Lin, C., and Treisman, D. (2009). Political decentralization and corruption: Evidence from around the world. Journal of Public Economics, 2009, 14-34.

Fisman, R., and Gatti, R. (2002). Decentralization and corruption: evidence across countries. Journal of Public Economics, 83, 325-345.

International Energy Agency (IEA). 2011. World Energy Outlook 2011. Paris: IEA.

IMF (2013). Energy subsidy reform in Sub-Saharian Africa. Experiences and lessons.

Joanis, M. (2014). Shared accountability and partial decentralization in local public good provision. Journal of Development Economics, 107, 28-37.

Kaufmann, D., Kraay A., and M. Mastruzzi. (2010). The Worldwide Governance Indicators : A Summary of Methodology, Data and Analytical Issues. World Bank Policy Research Working Paper No. 5430.

Keen, M., and Kotsogiannis, C. (2002). Does federalism lead to excessively high taxes?. American Economic Review, 92, 363-370.

Kessing, S., Konrad, K., and Kotsogiannis, C. (2007). Foreign direct investment and the dark side of decentralization. Economic Policy, 22, 6-70.

Kotsogiannis, C., and Rizzo, L. (2016). Fuel-price Subsidies and the control of corruption: A First approach. Strand, J. (Eds), The Economics and Political Economy of Energy Subsidies. MIT Press, 2016. CESifo-MIT Press.

Kotsogiannis, C., and Schwager, R. (2008). Accountability and fiscal equalization. Journal of Public Economics, 92, 2336-2349.

Kosmo, M. (1987). Money to burn? The high cost of energy subsidies. World Resources Institute, Washington, DC.

Larsen, B., and Shah, A. (1992). Carbon Taxes, the greenhouse effect and developing countries. World Bank Policy Research Working Paper Series N.957, The World Bank, Washington, DC. 
Mani, A., and Mukand, S. (2007). Democracy, visibility and public good provision. Journal of Development Economics, 83, 506-529.

Mundlak, Y. (1978). On the Pooling of Time Series and Cross Section Data. Econometrica, 46, 69-85.

Oates, W. (2005). Towards a second-generation theory of fiscal federalism. International Tax and Public Finance 12, 349-373.

OECD. (2010). The scope of fossil-fuel subsidies in 2009 and a road map for phasing-out fossil-fuel subsidies.

Panizza, U. (1999). On the determinants of fiscal centralization: Theory and evidence. Journal of Public Economics, 74, 97-139.

Riker, W. H. (1987). The development of American federalism. Boston: Kluwer.

Seabright, P. (1996). Accountability and decentralisation in government: An incomplete contracts model. European Economic Review, 40, 61-89.

Sorens, J. P. (2016). Secession risk and fiscal federalism. Publius, The Journal of Federalism, 46, 25-50.

Sterner, T. (2012). Fuel taxes and the poor: The distributional effects of gasoline taxation and their implications for climate policy. Washington, DC: Resources for the Future Press.

Treisman, D. (2000). Decentralization and the quality of government, available from https://www.imf.org/external/pubs/ft/seminar/2000/fiscal/treisman.pdf.

United Nations Environment Programme (UNEP) (2008). Reforming Energy Subsidies: Opportunities to Contribute to the Climate Change Agenda. Division of Technology, Industry and Economics, Paris.

Weingast, B. (2006). Second Generation Fiscal Federalism: Implications for Decentralized Democratic Governance and Economic Development, mimeo, Stanford University.

Wooldridge, J. M. (2009). Correlated random effects models with unbalanced panels. Manuscript (version July 2009) Michigan State University. 